\title{
Study on Combustion Oscillation of Premixed Flame with Pilot Fuel at Elevated Pressures"
}

\author{
Masaya OHTSUKA $^{* *}$, Shohei YOSHIDA ${ }^{* *}$, Yoshitaka HIRATA ${ }^{* *}$ \\ and Nariyoshi KOBAYASHI ${ }^{* * *}$ \\ **Energy and Environmental Systems Laboratory, Hitachi Ltd., \\ 7-2-1 Omika-cho, Hitachi-shi, Ibaraki-ken, 319-1221 Japan \\ E-mail: masaya.ohtsuka.qx@hitachi.com \\ ***Hitachi Research Laboratory, Hitachi Ltd., \\ 7-1-1 Omika-cho, Hitachi-shi, Ibaraki-ken, 319-1292 Japan
}

\begin{abstract}
Acoustically-coupled combustion oscillation is studied for premixed flame with pilot fuel to be used in gas turbine combustors. Premixed gas is passed through swirl vanes and burnt with the centrally injected pilot fuel. The dependencies of pressure, fuel to air ratio, premixed fuel rate, inlet velocity and air temperature on the combustion oscillation are investigated. Two kinds of oscillation modes of $\sim 100 \mathrm{~Hz}$ and $\sim 350 \mathrm{~Hz}$ are activated according to inlet velocities. Fluctuating pressures are amplified when the premixed fuel rate is over $\sim 80 \%$ at elevated pressures. The fluctuating pressure peak moves to a higher premixed fuel ratio region with increased pressure or fuel to air ratio for the Helmholz type mode. Combustion oscillation occurs when the pilot fuel velocity is changed proportionally with the flame length.
\end{abstract}

Key words: Combustion Oscillation, Premixed Flame, Pilot Fuel, Elevated Pressure, Premixed Fuel Rate, Flame Length

\section{Introduction}

Lowering NOx emission is one of the most important subjects for development of gas turbine combustors to react fossil fuels with air at high temperature. Premixed combustion has been widely used for this because flame temperature can be lowered under the thermal NOx generation temperature using dilute premixed flame. Premixed flame, however, tends to be extinguished in accordance with the reduction in fuel to air (F/A) ratio and flame temperature. Diffusion flame, on the other hand, has a high temperature region where NOx can be produced but this flame type is more stable than the premixed flame type. Both premixed and diffusion combustion systems, therefore, have been used to maintain operability of low NOx combustors. Diffusion combustion is preferable for boosting the power for a wide range of F/A ratios. Premixed combustion can be used from partial load to full load power for long-time operation, where NOx emission is limited. Switching from diffusion to premixed combustion can be done to change the power. Diffusion flame may be used as pilot flame to support unstable premixed flame even at regular power. Both premixed and diffusion mixed flames, therefore, can be present during combustor operation.

Acoustically-coupled oscillation of premixed flame has been studied for many burners and combustors. Simple ducted premixed flame has been studied for afterburners of jet aeroengines. ${ }^{1-3)}$ Mean and unsteady heat release rates were axially measured and analyzed 
using the one-dimensional linear stability analysis theory with appropriate flame models. The instability was related to the longitudinal acoustic mode and the unsteady heat release rate. The theory could predict the onset of the instability, oscillation modes and frequencies. These flame models have since been improved and non-linear stability analysis has been developed. ${ }^{4)} \quad$ Acoustically-coupled oscillations in gas turbine combustors have been investigated experimentally and analytically. ${ }^{5)-8)}$ In one analytical investigation $^{8)}$, the acoustically-coupled instability of premixed flame was modeled as combustion oscillation in low NOx gas turbine combustors at elevated pressures. In the same paper, a flame model for transfer matrix analysis was introduced, assuming the distribution of the mean heat release rate and the lag time through the flame as derived with the turbulent flame speed model.

Acoustically-coupled oscillation of premixed and diffusion mixed flame, on the other hand, has not been studied so much in spite of the importance of their engineering applications. Some premixed flames with pilot fuel were investigated for gas turbine combustors, ${ }^{9)-11)}$ but they have not been systematically studied. Anderson and Morford ${ }^{9)}$ stabilized a premixed flame and reduced the acoustic level by using a pilot fuel which moved the stabilization point closer to the nozzle exit. In the other two cases, premix flames obtained using pilot fuel were unstable due to pilot flame instability ${ }^{10)}$ or due to near blowout conditions. ${ }^{11)}$

In this study, the characteristics of the thermo-acoustic instability of premixed flame with pilot fuel are experimentally studied using a swirl premix burner at elevated pressures for application to gas turbine combustors. The dependencies of pressure, F/A ratio, premixed fuel rate, inlet velocity and air temperature on the combustion oscillation are studied.

\section{Nomenclature}

$A_{\mathrm{O} 2} \quad$ Mass Fraction of $\mathrm{O}_{2}$ in Air (-)

$C_{p} \quad$ Specific Heat Capacity $(\mathrm{J} / \mathrm{kgK})$

$D P \quad$ Root Mean Square of Fluctuating Pressure $(\mathrm{kPa})$

$E_{0} \quad$ Activation Energy (K)

$F \quad$ Total Fuel Flow Rate $(\mathrm{kg} / \mathrm{s})$

F2 Premixed Fuel Flow Rate $(\mathrm{kg} / \mathrm{s})$

$F 2 / F \quad$ Premixed Fuel Ratio (\%)

F1 Pilot Fuel Flow Rate $(\mathrm{kg} / \mathrm{s})$

$F / A \quad$ Fuel-to-Air Ratio (-)

$f \quad$ Frequency $(\mathrm{Hz})$

$L_{f} \quad$ Total Flame Length (m)

$M_{O 2} \quad$ Molecular Weight of $\mathrm{O}_{2}(\mathrm{~kg} / \mathrm{kmol})$

$P_{\text {in }} \quad$ Static Pressure (MPa)

$R_{t} \quad$ Turbulent Reynolds Number (-)

$r_{B} \quad$ Center Rod Radius of Burner (m)

$r_{o} \quad$ Air Path Outer Radius of Burner (m)

$S_{t} \quad$ Turbulent Flame Speed (m/s)

$S_{u} \quad$ Laminar Flame Speed $(\mathrm{m} / \mathrm{s})$

$t \quad$ Non-Dimensional Time Divided by the Period (-)

$T_{b} \quad$ Absolute Temperature on Burned Side of Flame (K)

$T_{u} \quad$ Absolute Temperature on Unburned Side of Flame (K)

$T_{\text {in }} \quad$ Air Temperature $\left({ }^{\circ} \mathrm{C}\right)$

U1 Pilot Fuel Axial Velocity at the Outlet of the Pilot Fuel Nozzle $(\mathrm{m} / \mathrm{s})$

$U 2, U_{2}$ Premixed Gas Axial Velocity at the Outlet of the Swirler $(\mathrm{m} / \mathrm{s})$ 
$Y \quad$ Fuel Mass Fraction (-)

$\alpha \quad$ Frequency Factor $\left(\mathrm{mol} / \mathrm{m}^{3} \mathrm{~s}\right)$

$\vartheta \quad$ Flame Angle (rad)

$\lambda$ Heat Conduction Rate $(\mathrm{W} / \mathrm{mK})$

$v \quad$ Laminar Kinematic Viscosity $\left(\mathrm{m}^{2} / \mathrm{s}\right)$

I Pilot Fuel or Flame

2 Premixed Gas or Flame

$f \quad$ Total Flame

\section{Test Facility}

3.1 Test Stand. Figure 1 shows the configuration of the test stand for investigating the characteristics of the combustion oscillation at elevated pressures. Combustion air is supplied from a compressor to a heat exchanger to raise its temperature to the experimental condition before entering the combustor. Methane flow is divided into two flow paths and the fuel flows are supplied into a premix fuel nozzle and a pilot fuel nozzle.

Fuel and air are mixed and burnt in the combustor and the burnt gas flows into a cooler through a choke orifice at one end of the combustor. The burnt gas is cooled by water injection in the cooler and discharged into the atmosphere. The pressure in the combustor is fixed by the opening area of the choke orifice.

The cylindrical combustor is cooled by water which flows in the surrounding annular space. The combustion chamber has a $\Phi 200 \mathrm{~mm}$ inner diameter and $1091.5 \mathrm{~mm}$ length. The premix fuel nozzle is installed upstream from the combustion chamber and the fuel is mixed with air. A baffle plate with $4 \%$ openings is installed to prevent back-fire. The premixed gas of desired F/A ratio is supplied through a tube ( $\Phi 66 \mathrm{~mm}$ inner diameter) to a swirl burner at the outlet of the premixer. Pilot fuel is introduced to the swirl burner from the pilot fuel nozzle.

The F/A distribution is measured to evaluate the F/A deviation by sampling tubes positioned at set intervals radially and circumferentially in the cross section of the premixer. The standard deviation of premix fuel concentration distribution is within $2 \%$ of $\mathrm{F} / \mathrm{A}$. Horizontal and vertical side views of the flames can be observed from two windows ( $\Phi 80$ $\mathrm{mm}$ inner diameter) in the combustion chamber wall and the flame images are obtained by a CCD camera. Pressures are measured at positions (1)-(6) using strain-gauge-type pressure transducers.

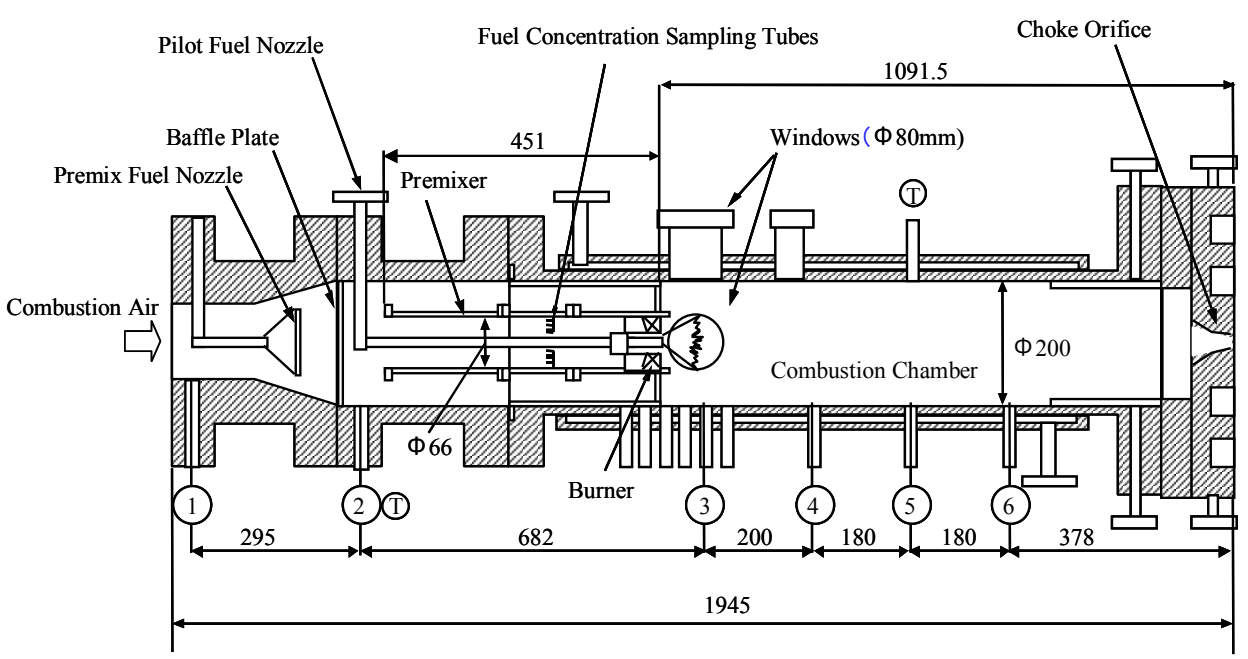

Figure 1 Combustion Test Stand 


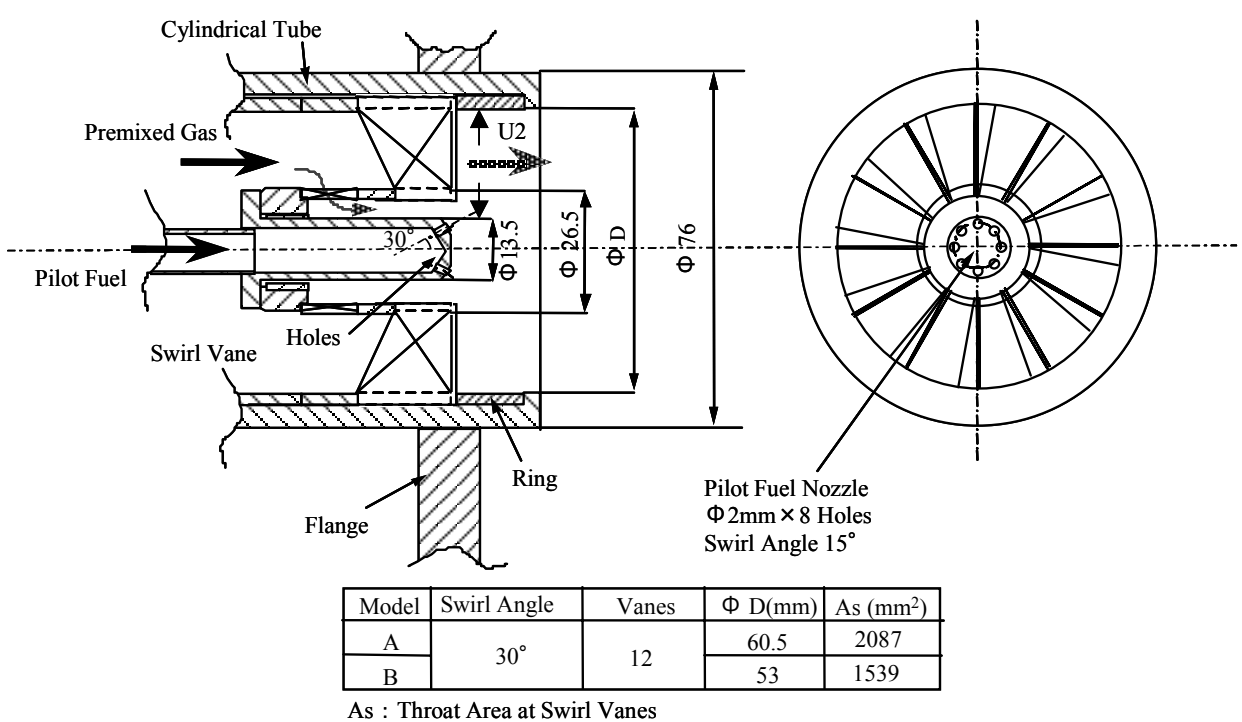

Figure 2 Swirl Burner

3.2 Swirl Burner. Figure 2 shows the structure of the swirl burner. The pilot fuel nozzle is located at the center of the burner and surrounded by the swirler which is composed of twelve swirl vanes of $30^{\circ}$ swirl angle. The pilot fuel nozzle has 8 holes of $\Phi 2 \mathrm{~mm}$ inner diameter and $15^{\circ}$ swirl angle. The premixed gas passes through the swirl vanes and is mixed and burnt with the pilot fuel. Three types of flames, therefore, are formed: the diffusion pilot flame, the premixed flame and the premixed flame with the pilot fuel. The outlet velocity of the swirler can be changed by inserting a spacer ring at the outlet. The premixed gas axial velocity $\mathrm{U} 2$ at the outlet of the burner is set to $\sim 30 \mathrm{~m} / \mathrm{s}$ (Model A) or $\sim 40 \mathrm{~m} / \mathrm{s}$ (Model B) in this study.

\section{Test Results and Discussions}

Test conditions for each measurement are shown in Table 1. Here, F2/F is the premixed fuel ratio, F2 is the premixed fuel flow rate and $F$ is the total fuel flow rate. F2/F is the parameter which characterizes the premixed flame with pilot fuel. The effects of pressure, F/A ratio, F2/F, inlet velocity and air temperature on the combustion oscillation are investigated in this study.

Table 1 Test Conditions

\begin{tabular}{|l|l|l|l|l|l|l|}
\hline Measurement & Burner Type & Tin $\left({ }^{\circ} \mathrm{C}\right)$ & F/A (-) & $\begin{array}{l}\text { Pin } \\
(\mathrm{MPa})\end{array}$ & F2/F (\%) & U2(m/s) \\
\hline \multirow{2}{*}{ Mode } & Model A & 302 & 0.04 & 1.0 & 70 & 33 \\
\cline { 2 - 7 } & Model B & 389 & 0.041 & 1.2 & 95 & 40 \\
\hline \multirow{2}{*}{$\begin{array}{l}\text { Temperature } \\
\text { Dependency }\end{array}$} & Model A & $235-385$ & 0.04 & 1.0 & $70-90$ & $23-30$ \\
\cline { 2 - 7 } & Model B & $235-385$ & 0.04 & 1.0 & $70-90$ & $31-42$ \\
\hline \multirow{2}{*}{$\begin{array}{l}\text { F/A } \\
\text { Dependency }\end{array}$} & Model A & 385 & $0.028-$ & 1.0 & $80-90$ & $30-33$ \\
\cline { 2 - 7 } & Model B & 385 & $0.029-$ & 1.1 & $80-90$ & $37-40$ \\
\hline \multirow{2}{*}{$\begin{array}{l}\text { Pressure } \\
\text { Dependency }\end{array}$} & Model A & 385 & 0.04 & $0.5-1.2$ & $70-95$ & 29 \\
\cline { 2 - 7 } & Model B & 385 & 0.04 & $0.5-1.2$ & $70-95$ & 40 \\
\hline \multirow{2}{*}{ Flame Length } & Model A & 385 & 0.0375 & 0.7 & $70-95$ & 33 \\
\cline { 2 - 7 } & Model B & 385 & 0.0375 & 0.9 & $70-95$ & 41 \\
\hline
\end{tabular}


4.1 Pressure Oscillation Mode. The dominant frequencies of pressure fluctuations are $\sim 100 \mathrm{~Hz}$ for Model A and $\sim 350 \mathrm{~Hz}$ for Model B. The two frequencies are observed for both models. The low frequency $\sim 100 \mathrm{~Hz}$ is dominant for the low premixed gas velocity $\sim 30 \mathrm{~m} / \mathrm{s}$ and the high frequency $\sim 350 \mathrm{~Hz}$ is dominant for the high premixed gas velocity $\sim 40 \mathrm{~m} / \mathrm{s}$.

Figure 3 shows transient states for the oscillation mode of $103 \mathrm{~Hz}$ during one period. The mode is measured by sampling pressure fluctuations at $0.5 \mathrm{~ms}$ intervals at multiple points simultaneously. The oscillation mode of $103 \mathrm{~Hz}$ is the first excited and it is a Helmholtz type quarter wave length mode which has a node in the premixing tube and an anti-node at the choke orifice. The pressure amplitude has the negative maximum in the combustor at $\mathrm{t}=0.0$, the minimum at $\mathrm{t}=0.21$, the positive maximum at $\mathrm{t}=0.52$ and the negative maximum again at $\mathrm{t}=1.03$. The pressures are out-of-phase between positions (2) and (3).
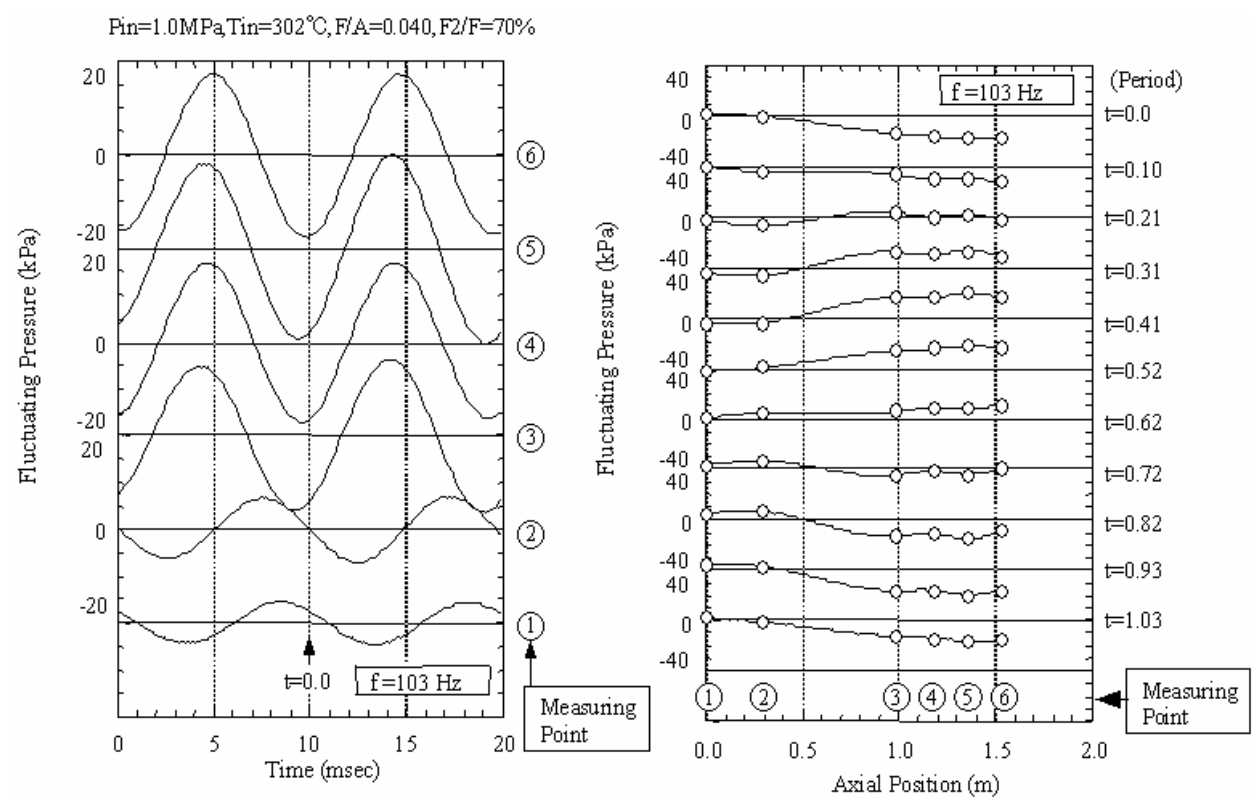

Figure 3 Pressure Mode (Model A)
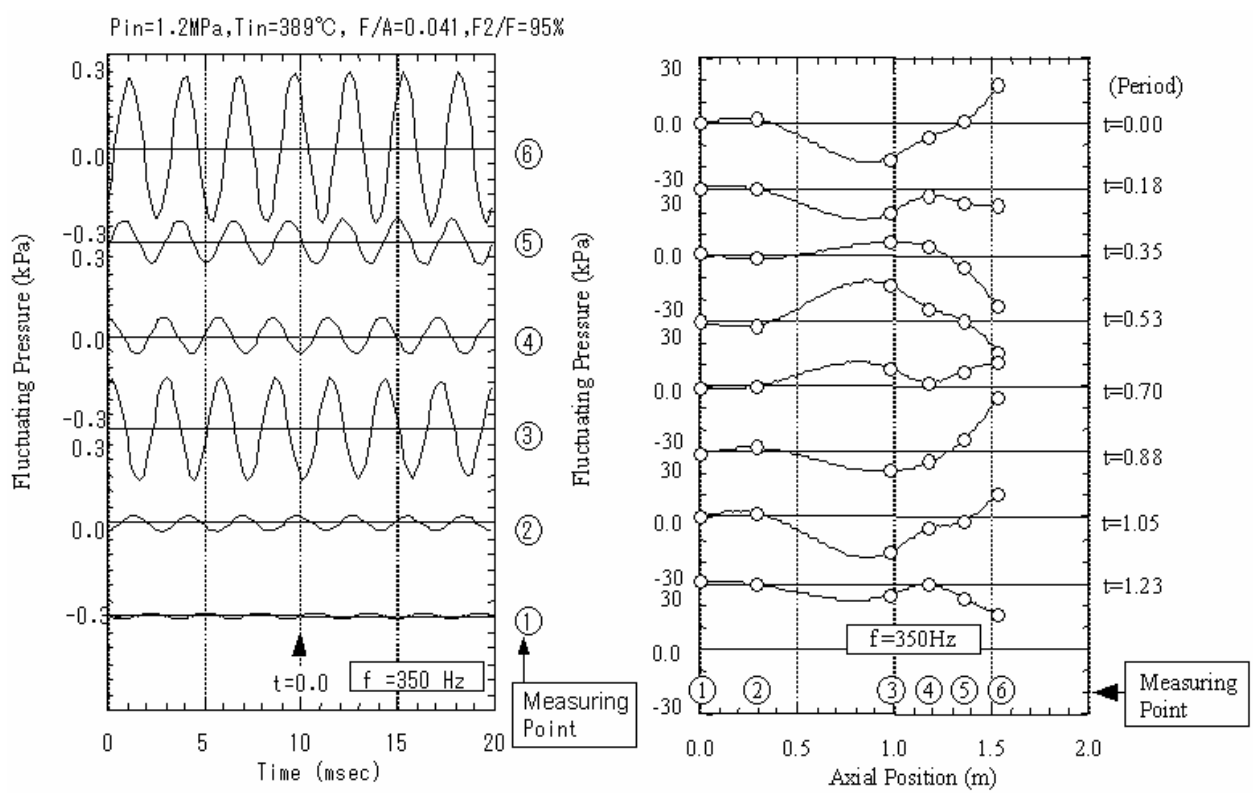

Figure 4 Pressure Mode (Model B) 
Figure 4 shows transient states for the oscillation mode of $350 \mathrm{~Hz}$ during one period. This mode is the second mode with antinodes both at the outlet of the burner and at the choke orifice and it is excited mainly in the combustor: no pressure fluctuation is strongly excited at positions (1) and (2) in the premix tube. The pressures are in-phase at positions (3) and (4) and at positions (5) and (6) but out-of-phase between positions (4) and (5).

The following results are evaluated at position (6) where both modes always have the anti-node.

4.2 Temperature Effect. The air temperatures are changed in the range of Tin=235 to $385^{\circ} \mathrm{C}$ (other test conditions, Table 1). The first mode is largely affected by air temperature. The decreasing temperature keeps the flame unstable which accelerates the acoustically-coupled instability. On the other hand, no combustion oscillation is developed by decreasing the temperature for Model B under the same conditions for Model A. The second mode is not sensitive to the temperature change under these test conditions. In the following tests, the inlet temperature $385^{\circ} \mathrm{C}$ is used to prevent low temperature instabilities for both models.

4.3 F/A Effect. Figures 5 and 6 show the F/A dependency of the fluctuating pressure for Models $\mathrm{A}$ and $\mathrm{B}$ at $\mathrm{F} / \mathrm{A}=0.028$ to 0.04 (other test conditions, Table 1). The premixed gas velocity is varied in the ranges of $30-33 \mathrm{~m} / \mathrm{s}$ for Model $\mathrm{A}$ and of $37-40 \mathrm{~m} / \mathrm{s}$ for Model $B$ according to the variation of F/A. The figures show the F/A dependency of the fluctuating pressure and the frequency at premixed fuel ratios of 80,85 and $90 \%$. In the large DP region, the amplitudes of the fluctuating pressure increase with F/A both for the first and the second modes because of the increase of burnt fuel. The resonant frequency also increases due to the increase of the temperature of the burnt gas. The F/A dependency of the amplitudes of the fluctuating pressure is changed with F2/F for Model A. The amplitude of fluctuating pressure of $\mathrm{F} 2 / \mathrm{F}=90 \%$ is the largest at large $\mathrm{F} / \mathrm{A}=0.039$ although the amplitude of fluctuating pressure of $\mathrm{F} 2 / \mathrm{F}=85 \%$ is the largest at small $\mathrm{F} / \mathrm{A}=0.035-0.037$. The fluctuating pressure peak of the first mode moves to higher $\mathrm{F} 2 / \mathrm{F}$ region with increased F/A.
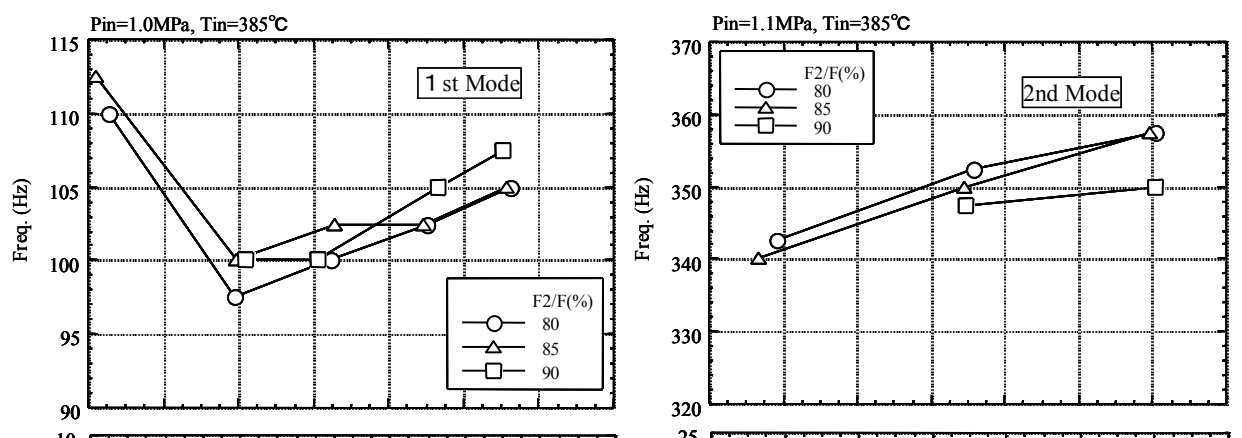

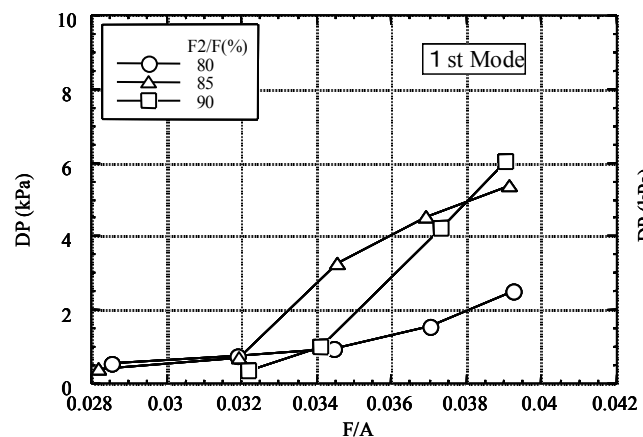

Figure 5 F/A Dependency of Fluctuating Pressure (Model A)

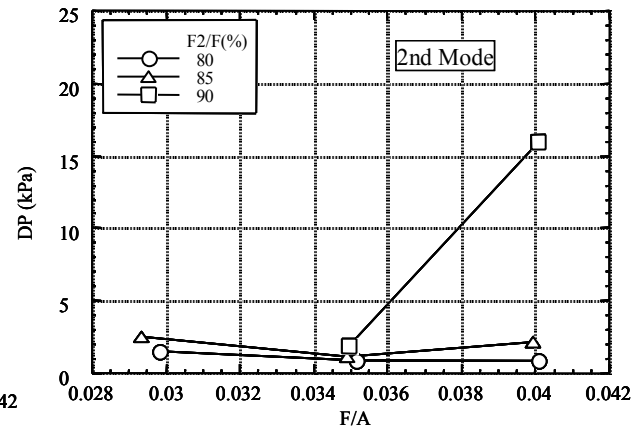

Figure 6 F/A Dependency of Fluctuating Pressure (Model B) 
4.4 Pressure Effect. Figures 7 and 8 show the pressure dependency of the fluctuating pressure amplitude and the frequencies for the first mode of Models A and B (other test conditions, Table 1). Figures 7 and 8 are analogous to Figs. 5 and 6. Amplitudes and the frequencies increase with pressure for both the first and second modes, which is the same trend as seen with the F/A. The pressure dependency of the amplitudes of the fluctuating

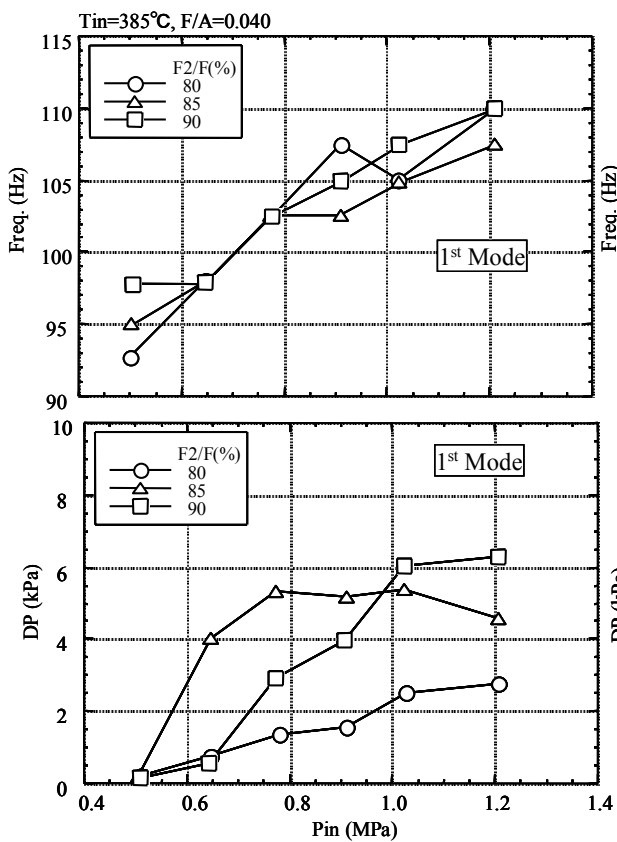

Figure 7 Pressure Dependency of Fluctuating Pressure (Model A)

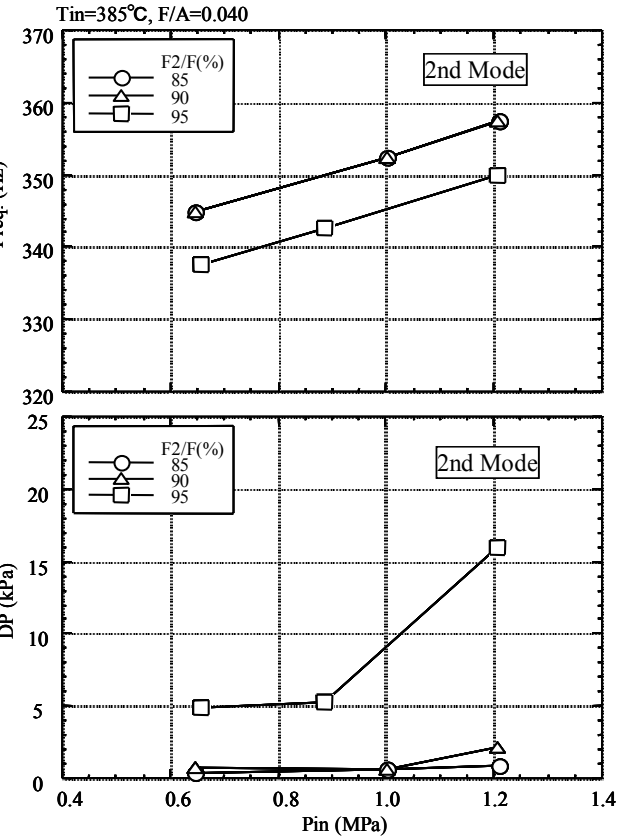

Figure 8 Pressure Dependency of Fluctuating Pressure (Model B)

$\operatorname{Tin}=385^{\circ} \mathrm{C}, \mathrm{F} / \mathrm{A}=0.040$
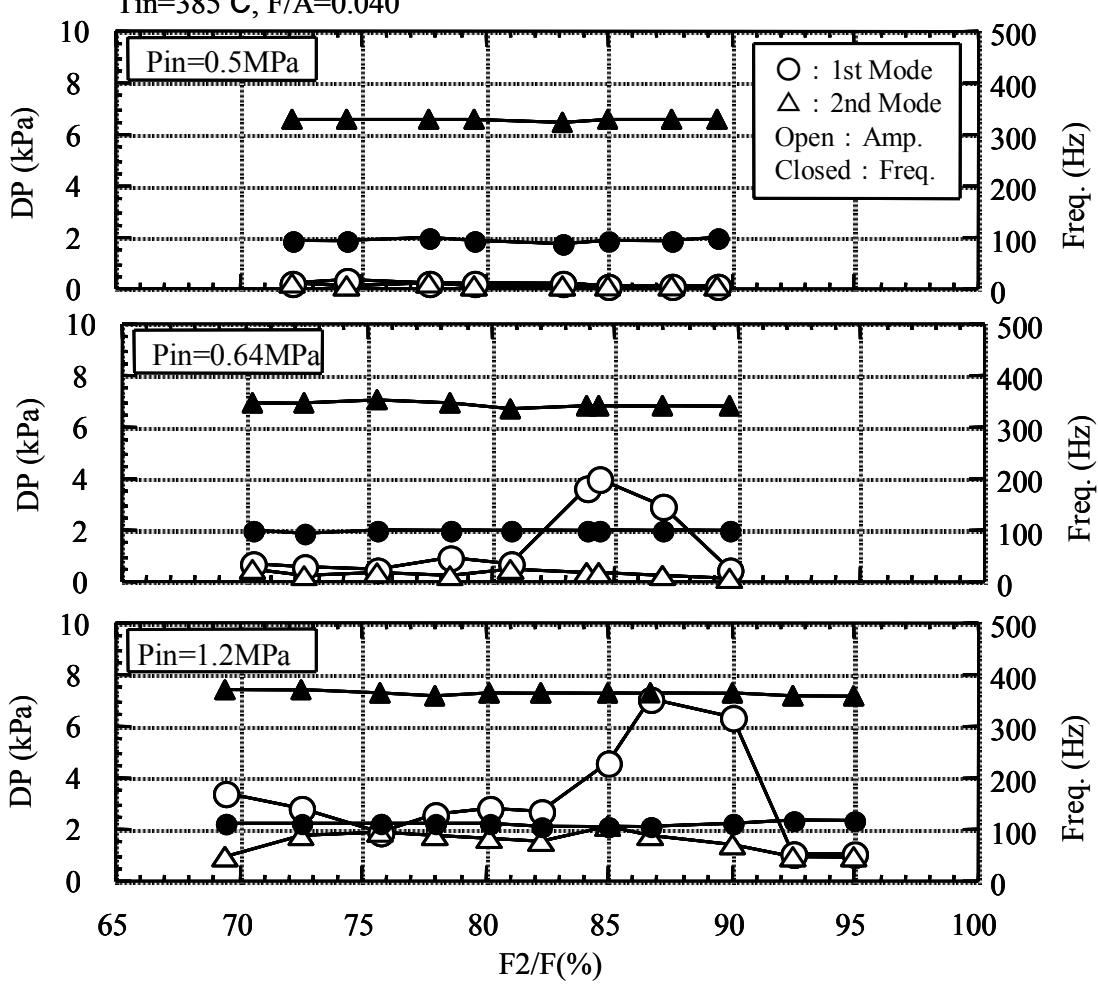

Figure 9 F2/F and Pressure Dependency of Fluctuating Pressure (Model A) 

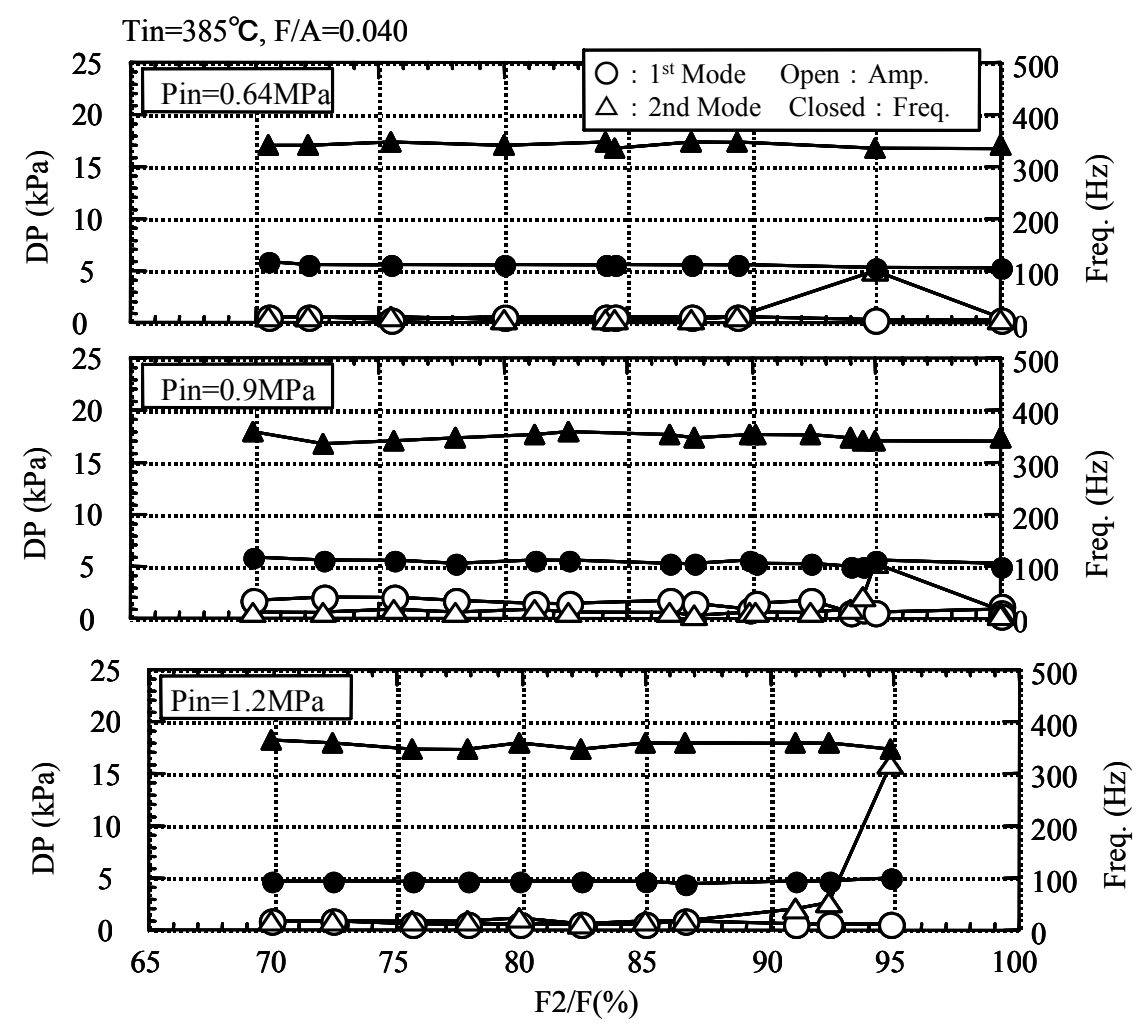

Figure 10 F2/F and Pressure Dependency of Fluctuating Pressure (Model B)

pressure is changed with $\mathrm{F} 2 / \mathrm{F}$ for Model A. The amplitude of fluctuating pressure of $\mathrm{F} 2 / \mathrm{F}=90 \%$ is the largest at large $\mathrm{Pin}=1.0-1.2$ although the amplitude of fluctuating pressure of $\mathrm{F} 2 / \mathrm{F}=85 \%$ is the largest at small $\mathrm{Pin}=0.64-0.9$. The fluctuating pressure peak of the first mode moves to higher $\mathrm{F} 2 / \mathrm{F}$ region with increased pressure. The pressure effect, therefore, is similar to the F/A effect.

The effect of pressure Pin is evaluated by changing the premixed fuel ratio F2/F more precisely. The results are shown in Fig. 9 for Model A. There is no significant peak between $\mathrm{F} 2 / \mathrm{F}=72.5$ to $90 \%$ at $0.5 \mathrm{MPa}$. The first mode is excited between $\mathrm{F} 2 / \mathrm{F}=80$ to $90 \%$ at $0.64 \mathrm{MPa}$. The pressure fluctuation amplitude of the first mode increases with pressure and there is a peak between $\mathrm{F} 2 / \mathrm{F}=82.5$ to $92.5 \%$ at $1.2 \mathrm{MPa}$. Combustion oscillation occurs in the specific region of $\mathrm{F} 2 / \mathrm{F}$.

Figure 10 shows the pressure fluctuation amplitude for Model B. The second mode has a peak around $\mathrm{F} 2 / \mathrm{F}=95 \%$. The combustion oscillation suddenly increases at $\mathrm{F} 2 / \mathrm{F}=95 \%$ and back-firing occurs for $\mathrm{F} 2 / \mathrm{F}$ greater than $95 \%$ at $1.2 \mathrm{MPa}$. There is no tendency for the fluctuating pressure peak to move on changing the premixed fuel ratio for the second mode.

4.5 Flame Length. For fully premixed flame, combustion oscillation characteristics are affected by the lag time through the fully premixed flame ${ }^{8)}$, which is related to the flame length. The flame length analysis is also applied in this study by using image processing of the flame pictures.

Figure 11 shows flame images of Models A and B. Here, flame images are obtained by the $\mathrm{CCD}$ camera with the $\mathrm{OH}$ radical filter to measure the reaction zone of the flame. The images show that the flame is short and wide for Model A and that the flame is long and narrow for Model B, which is affected by the outlet velocity of the burner. The light emission distributions for Model B are shown there as an example. The light emission distribution is triangular along the centerline of the image and the maximum is located near 


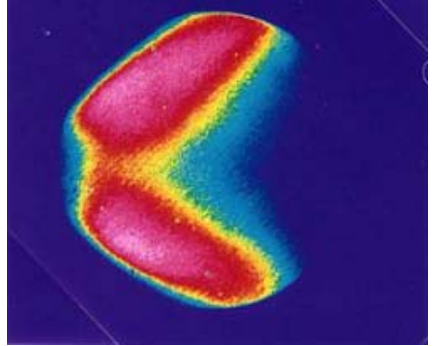

(a) Model A

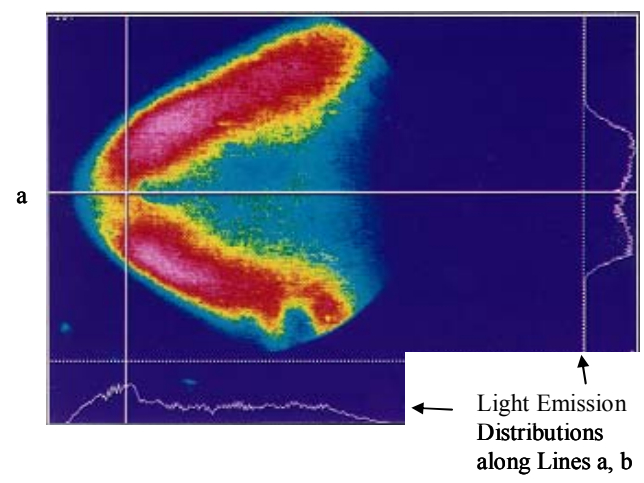

(b) Model B

( $\left.\mathrm{Pin}=0.7 \mathrm{MPa}, \operatorname{Tin}=385^{\circ} \mathrm{C}, \mathrm{F} / \mathrm{A}=0.0375, \mathrm{~F} 2 / \mathrm{F}=79 \%, \mathrm{U} 2=33 \mathrm{~m} / \mathrm{s}\right)$

$\left(\mathrm{Pin}=0.9 \mathrm{MPa}, \mathrm{Tin}=385^{\circ} \mathrm{C}, \mathrm{F} / \mathrm{A}=0.0375, \mathrm{~F} 2 / \mathrm{F}=81 \%, \mathrm{U} 2=41 \mathrm{~m} / \mathrm{s}\right)$

Figure 11 Flame Images (Time-Averaged)

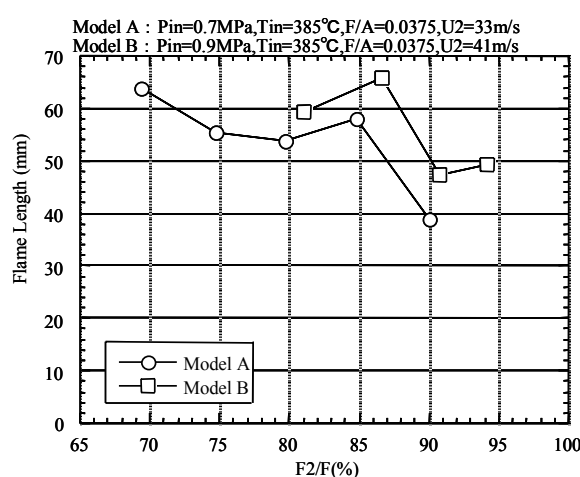

Figure 12 F2/F and Flame Length

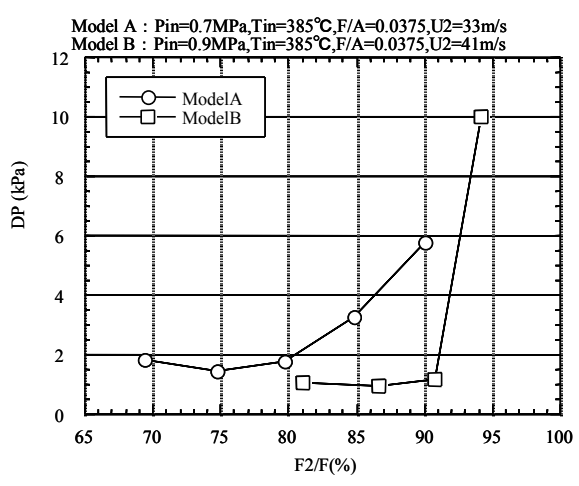

Figure 13 F2/F and DP

the anchor of the flame. The maximum of the light emission is located close to the flame tail without the pilot fuel ${ }^{8)}$ but near the flame front with the pilot fuel in this study. The pilot flame is not visible and the pilot fuel is mixed and burnt with premixed fuel near the flame front in the test conditions of high $\mathrm{F} 2 / \mathrm{F}$.

Figure 12 shows the flame length dependencies on the premixed fuel rate. Here, the flame length is defined as the distance from the burner outlet and the tail of the light emission of flame image. The flame length of Model A is shorter than that of Model B, which is affected by the outlet velocity of the burner. Figure 13 shows the amplitude of the fluctuating pressure at the same test conditions as Fig. 12. The local maximum of the flame length appears around $\mathrm{F} 2 / \mathrm{F}=85 \%$ due to the light emission growth but it is not related to the growth of combustion oscillation as shown in Fig. 13. The absolute value of the light emission is not connected to the onset of combustion oscillation but the combustion oscillation occurs when the flame length decreases.

The flame length and the combustion oscillation characteristics, therefore, are correlated for premixed flame with pilot fuel as well as for fully premixed flame. A flame length model, therefore, is introduced on the basis of the model for fully premixed flame. The following flame model was introduced for fully premixed turbulent flame of the swirl burner. $^{8)}$

$$
L_{f}=\sqrt{\frac{\left(r_{o}^{2}-r_{B}^{2}\right) U_{2} \cos \vartheta}{S_{t} \tan \vartheta}}
$$




$$
\begin{aligned}
& S_{t}=S_{u}\left\{1+\left(0.056 R_{t}\right)^{2}\right\}^{0.5} \\
& S_{u}=P_{\text {in }}-0.5 \sqrt{\frac{\lambda}{C_{p}} \frac{\alpha A_{O 2}}{M_{O 2}}\left\{Y_{2} \frac{1}{\chi}\left(\frac{T_{b}}{E_{0}}\right)^{2}+Y_{3} \frac{1}{\chi}\left(\frac{T_{u}}{E_{0}}\right)\right\} \exp \left(-\frac{E_{0}}{2 T_{b}}\right)} \\
& \chi=\frac{\left(T_{b}-T_{u}\right)}{T_{u}}
\end{aligned}
$$

Here, $\boldsymbol{L}_{\boldsymbol{f}}$ is the flame length and $\boldsymbol{S}_{\boldsymbol{t}}$ is the turbulent flame speed dependent on the laminar flame speed and the turbulent Reynolds number $\boldsymbol{R}_{\boldsymbol{t}}$. The dependency of pressure, F/A, and velocity can be considered through $\boldsymbol{S}_{\boldsymbol{t}}$ and flame angle $\vartheta$.

For fully premixed flame, F/A is equal to the fuel-to-air ratio of premixed gas. For premixed flame with pilot fuel, however, F/A is not equal to the fuel-to-air ratio of premixed gas because pilot fuel is burnt with premixed gas. Flame images in Fig. 11 show that pilot flame is not solely visible and the pilot fuel is mixed and burnt with premixed fuel. Then, the effective $\mathrm{F} / \mathrm{A}$ is defined by the following equation in this study, assuming that a part of pilot fuel is burnt with premixed flame.

$$
\left(\frac{F}{A}\right)_{\text {eff }}=\frac{1}{A}\left(F 2+F 1 \frac{F 2}{F}\right)
$$

The effective F/A approaches the total F/A as F2/F approaches $100 \%$, where almost all pilot fuel is burnt with premixed flame. The effective F/A changes proportionally to F2/A because premixed gas creates the main premixed flame which burns a part of the pilot fuel. Equation (5) satisfies these two conditions.

Turbulent Reynolds number $\boldsymbol{R}_{\boldsymbol{t}}$ is calculated for premixed flame with pilot fuel from the following equation.

$R_{t}=\left(\frac{0.20 U_{2}{ }^{r} B}{v}\right)^{0.62}$

Here, the constant 0.20 is fitted so that the calculated flame length agrees with the experimental data in this study although the constant was 0.14 for fully premixed flame ${ }^{8)}$

Figure 14 compares experimental and analytical flame lengths for Models A and B under the same conditions as Fig.12. Equation (5) is simple but the analytical flame length model can simulate the experimental flame length tendency at different $F 2 / F$, velocity $\mathrm{U} 2$ and pressure conditions except around the $\mathrm{F} 2 / \mathrm{F}=85 \%$ region which has a local light emission maximum.

Figure 15 shows the relationship between pilot fuel velocity U1 and flame length at fluctuating pressure peak. Here, the flame length is calculated using the present analytical flame model described by Eqs. (1)-(6). Combustion oscillation increases at short flame length with small $\mathrm{U} 1$ or at long flame length with large U1. Combustion oscillation occurs when the pilot fuel velocity is changed proportionally with the flame length. At low F/A or low pressure, flame length is relatively long and combustion oscillation increases at large U1. This condition is achieved at low F2/F. At high F/A or high pressure, flame length is relatively short and combustion oscillation increases at small U1. This condition is achieved at high F2/F. The fluctuating pressure peak, therefore, moves to the higher F2/F region with increased F/A or pressure.

Because pilot fuel velocity U1 is related to pilot fuel burning length, Fig. 15 also 


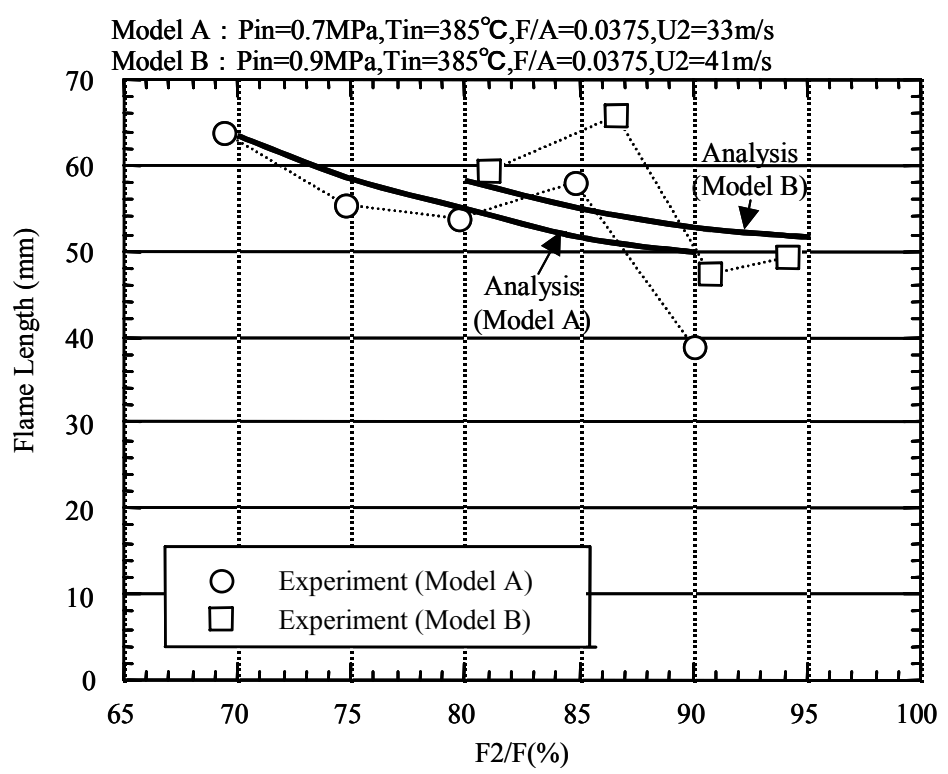

Figure 14 Comparison of Experimental and Analytical Flame Lengths

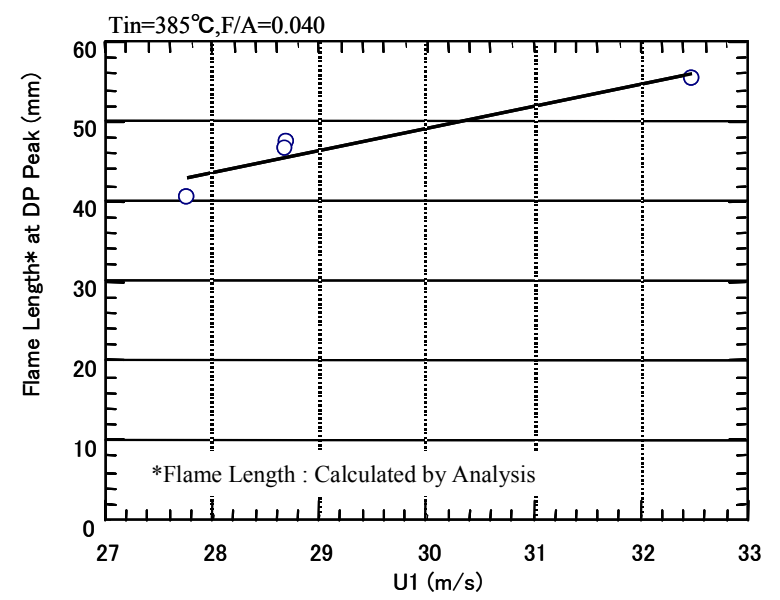

Figure 15 Relationship between U1 and Flame Length at DP Peak (Model A, 1st Mode)

indicates that combustion oscillation increases at short flame length with short pilot fuel burning length or at long flame length with long pilot fuel burning length. Fluctuating pressure due to combustion oscillation of premixed flame with pilot fuel, therefore, increases when premixed and pilot fuels are burnt in the close local region so that Rayleigh's criterion is satisfied, that is, the combustion oscillation occurs when the fluctuating pressure and the total fluctuating heat release rate are in phase for the oscillation period.

\section{Conclusions}

The dependencies of pressure, F/A ratio, premixed fuel rate, inlet velocity and air temperature on the combustion oscillation were clarified for premixed flame with pilot fuel using a swirl burner.

Two kinds of oscillation modes of $\sim 100 \mathrm{~Hz}$ and $\sim 350 \mathrm{~Hz}$ were activated according to inlet velocity. Fluctuating pressures were amplified when the premixed fuel rate was above $\sim 80 \%$ at elevated pressures. The first mode was the Helmholtz type mode and the fluctuating pressure peak moved to the higher F2/F region with increased F/A or pressure. 
The flame length of the premixed flame with pilot fuel was described by the corrected flame model of premixed flame, which introduces the effective F/A including the pilot fuel effect. Combustion oscillation occurred when the pilot fuel velocity was changed proportionally with the flame length for the first mode. Fluctuating pressure due to combustion oscillation of premixed flame with pilot fuel, therefore, increased when premixed and pilot fuels were burnt in the close local region so that the Rayleigh criterion was satisfied.

\section{References}

(1) P. J. Langhorne, Reheat Buzz: An Acoustically Coupled Combustion Instability, Part 1. Experiment, J. Fluid Mech. (1988) Vol.193, pp.417-443

(2) G.J. Bloxidge, A.P. Dowling and P.J. Langhorn, Reheat Buzz: An Acoustically Coupled Combustion Instability, Part 2. Theory, J. Fluid Mech. (1988) Vol.193, pp.445-473

(3) M. A. Macquisten and A.P. Dowling, Low-Frequency Combustion Oscillations in a Model Afterburner, Combust. Flame (1993) Vol.94, pp.253-264

(4) A.P. Dowling, Nonlinear Self-exited Oscillations of a Ducted Flame, J. Fluid Mech. (1997) Vol.346, pp.271-290

(5) J. J. Keller, Thermoacoustic Oscillations in Combustion Chambers of Gas Turbines, AIAA J. (1995) Vol. 33, No. 12, pp. 2280-2287

(6) C. O. Paschchereit and W. Polifke, Investigation of Thermoacoustic Characteristics of a Lean Premixed Gas Turbine Burner, ASME 98-GT-582, Int. Gas Turbine \& Aeroengine Congress and Exposition, Stockholm, Sweden, June 2-5, 1998

(7) U. Kruger et al., Prediction of Thermoacoustic Instabilities with Focus on the Dynamic Flame Behaviour for the 3A-Series Gas Turbine of Seimens KWU, ASME 99-GT-111, Int. Gas Turbine \& Aeroengine Congress and Exposition, Indianapolis, Indiana, June 7-10, 1999

(8) M. Ohtsuka et al., Combustion Oscillation Analysis of Premixed Flames at Elevated Pressures, JSME Int. J.(2005), Series B, Vol.48, No.3, pp.589-596

(9) T. J. Anderson and S. A. Morford, Dynamic Flame Structure in A Low NOx Premixed Combustor, ASME 98-GT-568, Int. Gas Turbine \& Aeroengine Congress and Exposition, Stockholm, Sweden, June 2-5, 1998

(10) C. O. Paschchereit and E. Gutmark, The Effectiveness of Passive Combustion Control Methods, GT-2004-53587, Proc. of ASME Turbo Expo 2004, Vienna, Austria, 2004

(11) S. Nair and T. Lieuwen, Acoustic Detection of Imminent Blowout in Pilot and Swirl Stabilized Combustors, GT-2003-38074, Proc. of ASME Turbo Expo 2003, Atlanta, U.S.A, 2003 